\title{
Oriented divisions, fate decisions
}

\author{
Scott E. Williams ${ }^{1}$ and Elaine Fuchs ${ }^{2, *}$ \\ ${ }^{1}$ Department of Pathology \& Laboratory Medicine, Lineberger Comprehensive Cancer Center, \\ University of North Carolina, Chapel Hill, NC 27599, USA. scott_williams@med.unc.edu \\ ${ }^{2}$ The Rockefeller University, New York, NY 10065, USA. fuchslb@rockefeller.edu
}

\begin{abstract}
During development, the establishment of proper tissue architecture depends upon the coordinated control of cell divisions not only in space and time, but also direction. Execution of an oriented cell division requires establishment of an axis of polarity and alignment of the mitotic spindle along this axis. Frequently, the cleavage plane also segregates fate determinants, either unequally or equally between daughter cells, the outcome of which is either an asymmetric or symmetric division, respectively. The last few years have witnessed tremendous growth in understanding both the extrinsic and intrinsic cues that position the mitotic spindle, the varied mechanisms in which the spindle orientation machinery is controlled in diverse organisms and organ systems, and the manner in which the division axis influences the signaling pathways that direct cell fate choices.
\end{abstract}

\section{Introduction}

Stem cells possess two important properties, multipotency and the capacity to self-renew. Often implied in this definition is that stem cells, particularly those present in the adult, persist for long periods of time, though quiescence is not necessarily a property of all stem cells [1]. Whether fast- or slow-cycling, stem cells can be stimulated to proliferate in response to injury or homeostatic needs. The transcriptional regulation of stem cell activation is a subject of great interest, but less well appreciated is the impact that division orientation plays in promoting and maintaining tissue architecture. The last 10 years have witnessed an explosion in the study of the molecular pathways that control mitotic spindle positioning and their role in promoting asymmetric cell divisions (ACDs).

Conceptually, ACDs are a simple way to balance self-renewal and differentiation. But in reality, the relation between spindle orientation and cell fate decisions is not necessarily linear or causal. As far back as a century ago, this conundrum was articulated by Edwin Conklin, who in the course of observing cell divisions in sea squirt oocytes noted that while "cleavage planes are, under normal conditions, constant in position and character, and bear a constant relation to the planes of differentiation...the factors which determine localization and those which determine the form of cleavage are more or less independent" [2]. With

(C) 2013 Elsevier Ltd. All rights reserved.

*To whom correspondence should be addressed: Elaine Fuchs, Howard Hughes Medical Institute, Laboratory of Mammalian Cell Biology \& Development, The Rockefeller University, 1230 York Avenue, Box 300, New York, NY, 10065, USA. Phone: 212-327-7953, Fax: 212-327-7954, fuchs@ rockefeller.edu.

Publisher's Disclaimer: This is a PDF file of an unedited manuscript that has been accepted for publication. As a service to our customers we are providing this early version of the manuscript. The manuscript will undergo copyediting, typesetting, and review of the resulting proof before it is published in its final citable form. Please note that during the production process errors may be discovered which could affect the content, and all legal disclaimers that apply to the journal pertain. 
enhanced knowledge of both the molecular complexes directing oriented cell divisions and the determinants instructing cell fate, it is becoming increasingly apparent that these two phenomena are often, but not always, coupled.

Thus, we wish to make it clear that the term "oriented cell division" is not synonymous with an "asymmetric" or "symmetric" cell division. In their strictest sense, ACDs involve the unequal partitioning of cellular components during division, resulting in daughter cells that differ molecularly and consequently adopt different fates. For a division to be oriented, it simply implies that an active process aligns the spindle along a particular axis, often determined by the intrinsic polarity of the cell. Both apicobasal and planar cell polarity (PCP) can influence division orientation, and as these topics have been the subject of excellent recent reviews [3-5], they will not be covered in detail here. That said, even if symmetric in partitioning cellular components, oriented cell divisions can result in differential fate decisions by virtue of displacing one progenitor daughter to a differentiation-inducing microenvironment (discussed later). This type of division, resulting in asymmetric fate outcomes through symmetric cell divisions, has sometimes been referred to as extrinsic asymmetric cell division. For the purposes of this review, we use the term ACD in its strictest sense, unless otherwise specified.

While much has been learned about the molecular machinery that directs oriented cell divisions in invertebrate systems such as Drosophila neuroblasts (NBs), sensory organ precursors (SOPs), and C. elegans embryos, comparatively little is known about how spindle orientation is controlled in vertebrates. That said, many core players central to the process in lower eukaryotes are also operative in diverse vertebrate organ systems such as the central nervous system, skin epidermis, lung bud epithelium, intestine, mammary gland, skeletal muscle satellite cells and dermomyotome [6-13]. These findings not only validate the evolutionary importance of this pathway, but also suggest that although the players may remain the same, the rules of the game frequently change.

\section{The old guard: the core molecular machinery regulating oriented cell divisions}

At the heart of the oriented cell division machinery are two complexes of proteins that localize to the apical cell cortex in many epithelial cells undergoing ACDs. These are the Par complex, consisting of Par3 (Baz in Drosophila), Par6 and aPKC, and the spindle orientation complex consisting of Gai, LGN/AGS-3 (Pins) and NuMA (Mud) (Figure 1). In some systems, these complexes are linked by the adapter protein mInsc (Insc), which can bind both Par3 and LGN. Through mechanisms that are not well understood, the microtubule-binding activity of NuMA, together with the motor protein complex dyneindynactin, are thought to exert the pulling forces on astral microtubules that reorient the mitotic spindle to align with apical polarity cues. Genetic studies in NBs have revealed that these components reinforce each other's cortical localization as well as that of basallyrestricted cell fate determinants, and that when absent, spindle orientation is perturbed. Evidence is mounting that several of the vertebrate homologs of these fly proteins-most notably LGN, mInsc, NuMA and dynactin - also play important roles in spindle orientation and the segregation of fate determinants.

Perhaps best studied are the radial glia (RG), the neural progenitors that reside in the subventricular zone (SVZ) of the developing cortex (reviewed in $[6,14]$ ). During early neurogenesis most RG divide symmetrically, with a planar orientation (e.g. parallel to the ventricular zone surface), generating two RG progeny. Later, RGs begin to adopt oblique orientations as well, though division angles of greater than $45^{\circ}$ are rare. Genetic and live imaging studies support the idea that oblique divisions generally result in asymmetric fate outcomes, generating one radial glia and one "committed" progenitor, either an intermediate/basal progenitor (IP), or an outer radial glia (oRG). Although oRGs are more 
common in primates than mice, both oRGs and IPs ultimately give rise to neurons-a process referred to as indirect neurogenesis — but it is believed that oRGs continue to divide asymmetrically while IPs divide symmetrically. In contrast"direct neurogenesis" is accomplished by the asymmetric planar division of RGs [15-18]. These studies thus raise several important points, namely that not all planar divisions are symmetric, and that some asymmetric divisions can result in two proliferative progenitors, one of which is stem-like and the other, a transiently proliferative intermediate, sometimes called a "transit-amplifying cell".

This complex interplay of division angles and cell fate choices is mirrored by variations in the mechanisms in which the core spindle orientation genes operate. For example, unlike other epithelia such as the embryonic epidermis and lung bud where LGN is oriented apically and promotes perpendicular divisions relative to the underlying basement membrane $[8,12,19]$, LGN in both the murine neocortex and chick neural tube is excluded from the apical cortex and instead forms a lateral belt, where together with NuMA, it functions in promoting planar divisions $[16,20 \bullet, 21]$ (Figure 2). On the other hand, though the expression of endogenous mInsc has not been characterized, epitope-tagged mInsc localizes apically, and several lines of evidence suggest that mInsc promotes oblique asymmetric divisions [21,22•]. Thus, in this case, the effects of LGN and mInsc in spindle orientation in RG are in fact opposite each other. Indeed, mInsc knockin phenocopies $L G N$ knockout in terms of increasing oblique/vertical divisions and generating more IPs. This seems to contrast with the epidermis, where epitope-tagged mInsc and LGN colocalize apically at mitosis, overexpression of mInsc promotes perpendicular divisons, and knockdown of LGN abolishes them [7,8].

Overall, these findings suggest that variations in the subcellular localization of complex members can endow them with vastly different cell-type specific roles in spindle orientation, and mInsc localization seems to be particularly critical. Interestingly, in the developing cortex, the requirement for mInsc is developmentally restricted, functioning in late but not early neurogenesis [22•]. Hence, it is tempting to speculate that its expression might be developmentally regulated as well. At present, the absence of satisfactory mInsc antibodies precludes ascertaining whether LGN forms lateral domains only in the absence of mInsc, whether the two proteins ever colocalize, and how mutations in one affect expression of the other. It will be of interest to see whether LGN and mInsc play similar or different roles in orienting the mitotic spindle and governing ACDs in other mammalian systems, particularly in developing epidermis where cell divisions progress from being primarily planar early to a mix of planar and perpendicular later in embryogenesis.

Further complicating matters is the finding that Insc is not simply a bridge between the Par3 and Gai-Pins-Mud pathways as once thought. Structural studies reveal that Insc, Pins/LGN, and Mud/NuMA do not form a ternary complex, and Insc and NuMA compete for binding to LGN, with mInsc showing a $>5$-fold higher affinity [23-27]. This leads to a model whereby Insc acts as a baton to hand-off LGN to NuMA, thus facilitating a switch from cortical polarization to microtubule reorganization.

\section{New directions in spindle orientation regulation}

Though the diversity of molecules to be implicated in spindle orientation is too wide to sufficiently address in this review, two other pathways merit discussion here: the phosphatase PP4 and the PDZ scaffolding protein Canoe (Cno). PP4 was identified in a genome wide screen in Drosophila for genes regulating neuroblast self-renewal, and $P p 4$ mutants show defective localization of the basal fate determinant Miranda [28,29]. More recently, the vertebrate homolog of PP4c was analyzed in neuronal progenitors and was found to be important for promoting self-renewing planar divisions, acting at least in part via 
the Ndel1/Lis1 microtubule-spindle complex [30•]. Unlike mInsc, which seems to function relatively late in cortical development to promote oblique and perpendicular divisions, PP4c seems to be required predominantly in early neurogenesis. Given that loss of $P P 4 c$ affects spindle orientation at all ages, but only fate decisions in early neurogenesis, it will be of interest to see if the Insc/Pins pathway synergizes with PP4c, and if so how.

Cno, the fly counterpart of AF-6/afadin, seems to operate between Pins and Mud in the spindle positioning pathway [31,32•]. In NBs, Cno is polarized at the apical cortex, and it is also required for proper fate determinant localization and division orientation [31]. Cno binds Ran ${ }^{\mathrm{GTP}}$, and it has been suggested that Cno/Ran facilitates the release of Mud from the nucleus by sequestering importin- $\beta$ away from the Mud NLS, thus allowing it to associate with Pins [32•]. This mechanism may be conserved in mammalian cells as well, as it has been shown that the Ran ${ }^{\text {GTP }}$-gradient negatively regulates the localization of LGN at the cell cortex in HeLa cells [33]. Cno also interacts with the small GTPase Rap1, and Rap1 mutant NBs cannot localize Cno properly and display spindle orientation errors [34•]. Interestingly, Cno and Rap1 are both essential to localize Baz cortically during cellularization [35]. This function may be conserved in NBs, given that Baz is frequently mislocalized in cno mutants [34॰] and that the Cno receptor Echinoid has been implicated in recruiting Baz to the zonula adherens [36]. Among its many other functions, Cno/afadin is an actin binding protein, so it will be of particular interest to determine whether afadin functions in vertebrate spindle orientation, where it might participate in the elusive link between the actomyosin network, apicobasal polarity complex, and spindle orientation machinery.

\section{It's not me, it's you: extrinsic regulators of spindle orientation}

Oriented cell divisions can be influenced by both intrinsic and extrinsic factors, though mechanistic understanding of the latter lags far behind the former [37]. Drosophila NBs are a prime example of a classical (i.e. intrinsic) ACD, as the plane of division is directed by the cell's own apicobasal polarity, which can be established even in isolated cells in culture. Extrinsic cues, on the other hand, can be provided by neighboring cells, frequently contributing to what is referred to as a stem cell "niche." Drosophila germline stem cells (GSCs) (reviewed in [38]) are perhaps the best-characterized example, where cap or hub cells are the source of instructive signals (BMP and Jak-Stat signaling) that are necessary to orient GSC mitotic spindles and ensure that the outcome of the division leads to an asymmetric fate (extrinsic ACD). Not all extrinsic signals require a niche, however. For example, the PCP pathway instructs the orientation of SOP divisions in the developing Drosophila peripheral nervous system. Interestingly, in SOP cells, the PCP spindle orientation pathway converges on the same core spindle orientation machinery that is required to orient NB divisions (e.g. Baz and Pins, reviewed in [37], as well as Cno and dynein [39]), while these genes have yet to be implicated in controlling GSC divisions.

The importance of stem cell niches is widely recognized in vertebrate systems [40], and one of the major signaling pathways that regulate stem cell quiescence and activation is the Wnt pathway [41]. Canonical Wnt signaling is activated when soluble Wnts bind Frizzled (Fz) receptors, which causes Dishevelled (Dsh/Dvl) to inhibit the activity of the GSK3 $\beta$ kinase/ apolyposis coli (APC)/Axin complex. One GSK3 $\beta$ substrate is $\beta$-catenin, which is stabilized upon canonical Wnt signaling/kinase silencing, allowing it to act as a transcription co-factor by associating with DNA binding proteins such as those of the Lef/Tcf family. Adding to the complexity of this circuitry, $\beta$-catenin can also regulate cell-cell adhesion at adherens junctions, and GSK3 3 has many substrates. Moreover, a distinct set of $\mathrm{Wnt} / \mathrm{Fz}$ proteins (e.g. Wnt5 and Fz6) signal via a non-canonical pathway, generally requiring Dvl but independent of APC/GSK3 $\beta / \beta$-catenin. Non-canonical Wnt signaling activates a diverse array of 
intracellular signaling pathways, one of which involves $\mathrm{Ca}^{2+} / \mathrm{CaMK} / \mathrm{NFAT}$, and inhibits canonical Wnt signaling.

Growing evidence suggests that Wnts may be a critical link between stem cell niche signaling and oriented cell divisions. In the early $C$. elegans embryo, extrinsic Wnt signaling was found to modulate spindle orientation through polarized inhibition of APC and GSK3 $\beta$, which in turn result in polarized stabilization and nuclear localization of $\beta$-catenin transcriptional complexes in only one of the two daughter cells $[42 \bullet, 43]$. Similarly, when bioactive Wnt3a beads were focally applied to one surface of a cultured human pluripotent embryonic stem cell, the mitotic spindle became oriented and nuclear $\beta$-catenin was detected solely in the daughter proximal to the Wnt signal [44•]. In another study, flamingo and Fz8, both players in noncanonical Wnt signaling, were shown to be important niche-derived factors with polarized activity that promote long-term hematopoietic stem cell (LT-HSC) quiescence in part by antagonizing canonical Wnt signaling [45].

The mechanisms by which Wnt signals are translated to the mitotic spindle are still unfolding, but a key player seems to be APC. Two studies have revealed altered spindle orientations in the intestinal stem cell compartment of mice which are mutant for $A p c$, a state which accomplishes much the same as sustained Wnt signaling [11,46]. Additionally, mutations in the fly APC homolog alter germ stem cell division angles [47]. Although these orientation defects have not been directly linked to Wnt signaling upstream or to spindle microtubules (MTs) downstream, cell migration studies suggest that APC may exert its influence on MTs through its interaction with the +TIP EB1, which helps load p150glued/ dynactin to MT ends [5,48]. Another interesting player is the actin-MT interacting spectraplakin, ACF7/MACF, which stabilizes MTs locally at a wound front [49]. The underlying mechanism appears to be through silencing the Wnt effector kinase GSK3 $\beta$, which otherwise phosphorylates and blocks ACF7/MACF from binding and stabilizing MTs in a directed fashion to repair the wound. Thus, it is tempting to speculate that Wnts, in addition to controlling the "activation state" of stem cells through $\beta$-catenin transcriptional targets, may also impact spindle orientation through the GSK3 $\beta$-regulated MT-binding activity of APC and ACF7.

Another theme that has emerged in recent years is the role that a different type of "niche", the extracellular matrix to which stem cells often adhere, plays in regulating fate decisions (reviewed in [50]). Biophysical properties of the ECM such as its stiffness have been shown to modulate the proclivity of a stem cell toward self-renewal or differentiation $[51,52]$. Moreover, work with micropatterned ECM substrates have confirmed the "Hertwig rule" that mechanical forces provided by polarized ECM attachment can also dictate division orientation [53,54]. In vivo studies continue to underscore the importance of cell-substrate adhesion in regulating spindle orientation. In both human and mouse, high levels of ECM receptors $\alpha \beta 1$ integrins are required for basal epidermal stem cells to maintain long-term proliferative potential [55,56], and $\beta 1$ mutations randomize their division orientations [19]. In Drosophila, integrins and their effectors were also found to be important regulators of ACDs in intestinal stem cells (ISCs) [57•] and in follicular stem cells [58]. Given that cell polarity directed by the apical Par and Pins/LGN complexes are also essential for both murine epidermal basal cell and Drosophila ISCs [8,57•], it seems that both intrinsic and extrinsic cues can cooperate to orient many stem cell divisions.

\section{From orientation to identity: signaling downstream of ACDs}

The first asymmetrically-inherited cell fate determinant described was Numb [59], later discovered to be an inhibitor of Notch signaling. Around the same time, one of the first descriptions of oriented cell divisions in a mammalian system was described for ferret SVZ neuronal precursors, and asymmetry in Notch1 inheritance was proposed to be a determinant 
that promotes different cell fates between apical and basal daughters [60]. These studies, along with the identification by Kemphues and colleagues of the pargenes in the $C$. elegans embryo [61,62], paved the way for the molecular genetic revolution that followed, in which much of what we now know about the spindle orientation pathway was discovered through examination of these fly and worm systems. This popularized the view that spindle orientation and cell fate are causally related, and that differential activation of the Notch pathway in particular is the lynchpin that links them. Yet, the mechanism by which this is accomplished remained poorly understood outside of SOP cells $[63-65,66 \bullet, 67]$.

This has changed in recent years as increasing evidence has mounted in vertebrate systems to demonstrate that oriented cell divisions can direct asymmetric Notch activation, largely through the use of GFP-based reporters [68]. One of the first studies to show this examined the consequences of Par3 loss on neuronal progenitors [69]. Par3 was shown to be important for both cell fate and Notch activity, though a direct link to spindle orientation was lacking. More recently, we have shown that eliminating perpendicular divisions in basal epidermal progenitors through the knockdown of $L G N$ or Numal not only shifts the balance between basal cells and their differentiating suprabasal (spinous) progeny, but also markedly attenuates suprabasal expression of the Notch target Hes1 as well as Notch reporter activity [8]. Moreover, we confirmed through genetic studies that LGN and Notch act in a common, likely linear pathway, and that resupplying active Notch can rescue LGN-mediated spinous differentiation defects. Similar results have now been reported in the mouse distal lung bud epithelium [12], chick neural tube [70] and Drosophila ISCs [57•].

These studies reveal a common link between oriented cell divisions and Notch activation, yet there remain multiple theories about the mechanism by which this is accomplished. Are Notch pathway components asymmetrically distributed during mitosis (i.e. classical ACDs)? Or is the signaling in daughter cells differentially activated following cell division, perhaps due to extrinsic cues (the signaling "milieu") present in the environment of one daughter but not the other? Current evidence suggests that both processes may occur.

Numb remains a prime candidate to selectively inhibit Notch signals in one daughter, and it appears to be a critical player in SOP and NB ACDs. However, convincing evidence is lacking in other systems, particularly vertebrates, as Numb does not appear to be asymmetrically distributed in either the murine epidermis or Drosophila ISCs [8,57•]. Although Numb plays a role in neurogenesis, it is believed that this function may not be directly related to oriented cell divisions, and that Numb acts rather to affect the endocytosis and recycling of adherens junction components [71]. In muscle satellite stem cells, identified by a BrdU label-retention strategy, Numb has been shown to asymmetrically segregate at mitosis [72]. However, using a different set of markers (Myf5-/Pax7+), another group failed to observe any differences in Numb expression between satellite stem cells and their differentiating progeny [73].

Evidence is also mounting that asymmetric Notch activity can be acquired by other means. In muscle satellite cells for example, Notch3 is elevated in stem cells while the ligand Dll1 is enriched in committed progeny [73]. In murine neuronal stem cells (NSCs), Dll1 is asymmetrically inherited at mitosis, and distinguishes activated stem cells that reside in close proximity to quiescent stem cells [74]. In zebrafish NSCs, the apical daughter retains higher levels Notch ligand as well as the E3 ubiquitin ligase mind bomb (Mib), which ensure that higher Notch levels are maintained in the basal, differentiating daughter [75•]. These studies reveal that directional Notch signals may function not only during mitosis, but also following it to reinforce fate acquisition. Interestingly, $\beta 1$-integrin ${ }^{\text {hi }}$ epidermal stem cells also show elevated levels of Dll1 [55], suggesting that this heterogeneity and intralineage commitment may operate in other systems as well. 
Finally, though much attention has been focused on Notch and Numb, two recent studies have shown that the mammalian homologs of other Drosophila basal proteins are noteworthy. In NBs, Staufen functions as an RNA-binding protein that binds to the 3' UTR of prospero RNA, one of the basal determinants-along with Numb, Miranda, and Bratthat promote the (non-NB) ganglion mother cell fate. Mammalian stauffen2 is asymmetrically inherited by neuronal progenitors, binds homologs of the fly basal determinants prospero and brat, and leads to premature differentiation of radial glial progenitors when knocked-down $[76 \bullet, 77 \bullet]$. These data suggest that the NB pathway may be more highly conserved than originally thought. Adding further intrigue is the observation that mammalian staufens can bind not only to mRNAs, but also long non-coding RNAs (lncRNAs) [78]. Intriguingly, one such binding partner is the lncRNA TINCR, which has been shown to be important for epidermal differentiation [79].

\section{Conclusions}

Much of the headway in pioneering the molecular machinery that drives oriented cell divisions was made through genetic studies in invertebrate systems. Now the knowledge of stem cell biology and increasing genetic prowess of the mouse are helping to forge a new era of research in oriented cell divisions. One challenge for the future will be to understand how spindle orientation is controlled in organ systems where the balance between symmetric and asymmetric fate outcomes is dynamically regulated. Are there external cues that influence these choices, or is the decision to self-renew or differentiate based more on space availability, mechanical tension, or competition for niche occupancy? How much of a role will differential exposure to external cues influence these choices? While a detailed discussion of these models is beyond the scope of this review, we would be remiss not to mention that there is growing evidence that stochastic decisions also influence the balance between symmetric and asymmetric divisions and cell fate outcomes. Especially in the context of adult epithelial stem cells, "population" rather than "cellular" asymmetry has been shown by lineage tracing and computational methods to account for the long-term homeostasis of tissues with rapid turnover [80-82]. These insightful models, though invaluable for directing hypothesis testing, identify and assume the existence of a single class of highly proliferative progenitors. Thus, their predictive value is diminished in hierarchical models where a long-term quiescent stem cell exists, or during development where the objective is tissue expansion rather than maintenance. Nonetheless, population and cellular asymmetry need not be mutually exclusive, as it is important to point out that these models do not rule out the existence of active molecular mechanisms to transduce environmental space cues to the mitotic spindle. Perhaps the Hippo pathway may be one attractive rectifier, as this master regulator of organ size may be linked to spindle orientation through a-E-catenin and merlin/NF-2 [83-85].

Another challenge will be to shift from a developmental to a translational focus. Imbalances in stem cell divisions have been linked to dysregulated growth [48,86,87], but is the link between defective cell polarity/spindle orientation and cancer progression correlative or causal? Several recent studies have shown promise in this arena, implicating the polarity protein Par3 as a modifier of squamous cell carcinoma growth. However, it is not known whether these effects are related to spindle orientation errors or some other function of Par3, such as adhesion or Ras signaling [88-90].

Taking a step back, there is still a basic science knowledge gap between invertebrates and vertebrates, particularly with regard to apicobasal polarity proteins. For example, Par3 knockout mice seem surprisingly normal [90,91], but is this a function of divergent roles for the Par complex in stratified versus simple epithelia? Even less is known about other polarity complexes: Crumbs/Stardust (Pals1)/Patj and Dlg/Scribble/Lgl. In addition, while 
much has been learned about the cortical complexes that help ensure asymmetry in cell fate determination, the signaling pathways that direct cleavage furrow positioning and daughter cell size asymmetry are just beginning to be unraveled [92,93•]. The future holds much work, but also promise, if we can divide and conquer, and remain oriented.

\section{Acknowledgments}

We wish to thank all members of the Fuchs lab for helpful discussions, and Juergen Knoblich for critical reading of the manuscript. We apologize to those colleagues whose work we were unable to cite due to space constraints. S.E.W. was supported by an American Cancer Society postdoctoral fellowship. E.F. is an investigator in the Howard Hughes Medical Institute and received support from NIH grant (R37AR27883) for the studies leading to this review.

\section{References}

- of special interest

1. Clevers H. The intestinal crypt, a prototype stem cell compartment. Cell. 2013; 154:274-284. [PubMed: 23870119]

2. Conklin EG. Organisation and cell-lineage of the ascidian egg. Proceedings of the Academy of Natural Sciences of Philadelphia. 1905; 13(1-119)

3. Wallingford JB. Planar cell polarity and the developmental control of cell behavior in vertebrate embryos. Annu Rev Cell Dev Biol. 2012; 28:627-653. [PubMed: 22905955]

4. Morin X, Bellaiche Y. Mitotic spindle orientation in asymmetric and symmetric cell divisions during animal development. Dev Cell. 2011; 21:102-119. [PubMed: 21763612]

5. Lu MS, Johnston CA. Molecular pathways regulating mitotic spindle orientation in animal cells. Development. 2013; 140:1843-1856. [PubMed: 23571210]

6. Lancaster MA, Knoblich JA. Spindle orientation in mammalian cerebral cortical development. Curr Opin Neurobiol. 2012

7. Poulson ND, Lechler T. Robust control of mitotic spindle orientation in the developing epidermis. $\mathbf{J}$ Cell Biol. 2010; 191:915-922. [PubMed: 21098114]

8. Williams SE, Beronja S, Pasolli HA, Fuchs E. Asymmetric cell divisions promote Notch-dependent epidermal differentiation. Nature. 2011; 470:353-358. [PubMed: 21331036]

9. Ben-Yair R, Kahane N, Kalcheim C. LGN-dependent orientation of cell divisions in the dermomyotome controls lineage segregation into muscle and dermis. Development. 2011; 138:4155-4166. [PubMed: 21852400]

10. Brack AS, Rando TA. Tissue-specific stem cells: lessons from the skeletal muscle satellite cell. Cell Stem Cell. 2012; 10:504-514. [PubMed: 22560074]

11. Quyn AJ, Appleton PL, Carey FA, Steele RJ, Barker N, Clevers H, Ridgway RA, Sansom OJ, Nathke IS. Spindle orientation bias in gut epithelial stem cell compartments is lost in precancerous tissue. Cell Stem Cell. 2010; 6:175-181. [PubMed: 20144789]

12. El-Hashash AH, Turcatel G, Al Alam D, Buckley S, Tokumitsu H, Bellusci S, Warburton D. Eya1 controls cell polarity, spindle orientation, cell fate and Notch signaling in distal embryonic lung epithelium. Development. 2011; 138:1395-1407. [PubMed: 21385765]

13. Cicalese A, Bonizzi G, Pasi CE, Faretta M, Ronzoni S, Giulini B, Brisken C, Minucci S, Di Fiore PP, Pelicci PG. The tumor suppressor $\mathrm{p} 53$ regulates polarity of self-renewing divisions in mammary stem cells. Cell. 2009; 138:1083-1095. [PubMed: 19766563]

14. Peyre E, Morin X. An oblique view on the role of spindle orientation in vertebrate neurogenesis. Dev Growth Differ. 2012; 54:287-305. [PubMed: 22524602]

15. Noctor SC, Martinez-Cerdeno V, Ivic L, Kriegstein AR. Cortical neurons arise in symmetric and asymmetric division zones and migrate through specific phases. Nat Neurosci. 2004; 7:136-144. [PubMed: 14703572]

16. Shitamukai A, Konno D, Matsuzaki F. Oblique radial glial divisions in the developing mouse neocortex induce self-renewing progenitors outside the germinal zone that resemble primate outer subventricular zone progenitors. J Neurosci. 2011; 31:3683-3695. [PubMed: 21389223] 
17. Hansen DV, Lui JH, Parker PR, Kriegstein AR. Neurogenic radial glia in the outer subventricular zone of human neocortex. Nature. 2010; 464:554-561. [PubMed: 20154730]

18. Fietz SA, Kelava I, Vogt J, Wilsch-Brauninger M, Stenzel D, Fish JL, Corbeil D, Riehn A, Distler W, Nitsch R, et al. OSVZ progenitors of human and ferret neocortex are epithelial-like and expand by integrin signaling. Nat Neurosci. 2010; 13:690-699. [PubMed: 20436478]

19. Lechler T, Fuchs E. Asymmetric cell divisions promote stratification and differentiation of mammalian skin. Nature. 2005; 437:275-280. [PubMed: 16094321]

20. Peyre E, Jaouen F, Saadaoui M, Haren L, Merdes A, Durbec P, Morin X. A lateral belt of cortical LGN and NuMA guides mitotic spindle movements and planar division in neuroepithelial cells. $\mathrm{J}$ Cell Biol. 2011; 193:141-154. [PubMed: 21444683] Demonstrates that a lateral cortical belt of LGN expression promotes planar cell divisions in chick neuroepithelial cells. Perturbing LGN, NuMA or Gai1/2/3 function leads to randomization of spindle orientation and ectopic progenitors.

21. Konno D, Shioi G, Shitamukai A, Mori A, Kiyonari H, Miyata T, Matsuzaki F. Neuroepithelial progenitors undergo LGN-dependent planar divisions to maintain self-renewability during mammalian neurogenesis. Nat Cell Biol. 2008; 10:93-101. [PubMed: 18084280]

22. Postiglione MP, Juschke C, Xie Y, Haas GA, Charalambous C, Knoblich JA. Mouse inscuteable induces apical-Basal spindle orientation to facilitate intermediate progenitor generation in the developing neocortex. Neuron. 2011; 72:269-284. [PubMed: 22017987] Through conditional knockout and overexpression of the mouse homolog of Inscuteable in cortical progenitors, the authors show that mInsc promotes oblique divisions and the generation of basal and intermediate progenitors.

23. Culurgioni S, Alfieri A, Pendolino V, Laddomada F, Mapelli M. Inscuteable and NuMA proteins bind competitively to Leu-Gly-Asn repeat-enriched protein (LGN) during asymmetric cell divisions. Proc Natl Acad Sci U S A. 2011; 108:20998-21003. [PubMed: 22171003]

24. Mauser JF, Prehoda KE. Inscuteable regulates the Pins-Mud spindle orientation pathway. PLoS One. 2012; 7:e29611. [PubMed: 22253744]

25. Pan Z, Zhu J, Shang Y, Wei Z, Jia M, Xia C, Wen W, Wang W, Zhang M. An Autoinhibited Conformation of LGN Reveals a Distinct Interaction Mode between GoLoco Motifs and TPR Motifs. Structure. 2013

26. Yuzawa S, Kamakura S, Iwakiri Y, Hayase J, Sumimoto H. Structural basis for interaction between the conserved cell polarity proteins Inscuteable and Leu-Gly-Asn repeat-enriched protein (LGN). Proc Natl Acad Sci U S A. 2011; 108:19210-19215. [PubMed: 22074847]

27. Zhu J, Wen W, Zheng Z, Shang Y, Wei Z, Xiao Z, Pan Z, Du Q, Wang W, Zhang M. LGN/mInsc and LGN/NuMA complex structures suggest distinct functions in asymmetric cell division for the Par3/mInsc/LGN and Galphai/LGN/NuMA pathways. Mol Cell. 2011; 43:418-431. [PubMed: 21816348]

28. Sousa-Nunes R, Chia W, Somers WG. Protein phosphatase 4 mediates localization of the Miranda complex during Drosophila neuroblast asymmetric divisions. Genes Dev. 2009; 23:359-372. [PubMed: 19204120]

29. Neumuller RA, Richter C, Fischer A, Novatchkova M, Neumuller KG, Knoblich JA. Genomewide analysis of self-renewal in Drosophila neural stem cells by transgenic RNAi. Cell Stem Cell. 2011; 8:580-593. [PubMed: 21549331]

30. Xie Y, Juschke C, Esk C, Hirotsune S, Knoblich JA. The Phosphatase PP4c Controls Spindle Orientation to Maintain Proliferative Symmetric Divisions in the Developing Neocortex. Neuron. 2013 This study identifies a new player in vertebrate spindle orientation through analysis of cortex specific $P p 4 c$ knockout mice. Pp4c promotes planar divisions in early neurogenesis, likely by dephosphorylating Ndel1, which facilitates its interaction with the spindle orientation complex through Lis1.

31. Speicher S, Fischer A, Knoblich J, Carmena A. The PDZ protein Canoe regulates the asymmetric division of Drosophila neuroblasts and muscle progenitors. Curr Biol. 2008; 18:831-837. [PubMed: 18499457]

32. Wee B, Johnston CA, Prehoda KE, Doe CQ. Canoe binds RanGTP to promote Pins(TPR)/Mudmediated spindle orientation. J Cell Biol. 2011; 195:369-376. [PubMed: 22024168] This paper builds on previous studies from the Carmeña lab implicating the afadin homolog Cno in neuroblast ACDs. Using the $\mathrm{S} 2$ cell induced polarity assay, this study goes on to show that Cno directly binds 


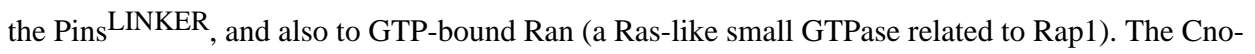
Ran pathway is required for facilitating the interaction of Pins with Mud.

33. Kiyomitsu T, Cheeseman IM. Chromosome- and spindle-pole-derived signals generate an intrinsic code for spindle position and orientation. Nat Cell Biol. 2012; 14:311-317. [PubMed: 22327364]

34. Carmena A, Makarova A, Speicher S. The Rap1-Rgl-Ral signaling network regulates neuroblast cortical polarity and spindle orientation. J Cell Biol. 2011; 195:553-562. [PubMed: 22084305] This paper provides further evidence that Cno is an important player in Drosophila neuroblast spindle orientation, here implicating the Ras-like GTPase Rap1 and RalGEF Rgl as acting upstream of Cno in the pathway.

35. Choi W, Harris NJ, Sumigray KD, Peifer M. Rap1 and Canoe/afadin are essential for establishment of apical-basal polarity in the Drosophila embryo. Mol Biol Cell. 2013; 24:945-963. [PubMed: 23363604]

36. Wei SY, Escudero LM, Yu F, Chang LH, Chen LY, Ho YH, Lin CM, Chou CS, Chia W, Modolell $\mathrm{J}$, et al. Echinoid is a component of adherens junctions that cooperates with DE-Cadherin to mediate cell adhesion. Dev Cell. 2005; 8:493-504. [PubMed: 15809032]

37. Werts AD, Goldstein B. How signaling between cells can orient a mitotic spindle. Semin Cell Dev Bio. 2011

38. Spradling A, Fuller MT, Braun RE, Yoshida S. Germline stem cells. Cold Spring Harb Perspect Biol. 2011; 3:a002642. [PubMed: 21791699]

39. Johnston CA, Manning L, Lu MS, Golub O, Doe CQ, Prehoda KE. Formin-mediated actin polymerization cooperates with Mud/Dynein during Frizzled/Dishevelled spindle orientation. J Cell Sci. 2013

40. Wagers AJ. The stem cell niche in regenerative medicine. Cell Stem Cell. 2012; 10:362-369. [PubMed: 22482502]

41. Clevers H, Nusse R. Wnt/beta-catenin signaling and disease. Cell. 2012; 149:1192-1205. [PubMed: 22682243]

42. Sugioka K, Mizumoto K, Sawa H. Wnt regulates spindle asymmetry to generate asymmetric nuclear beta-catenin in C. elegans. Cell. 2011; 146:942-954. [PubMed: 21925317] This study in the $C$. elegans embryo that an extrinsic Wnt signal can induce cytoskeletal remodeling through the effect of APC on astral MTs, which promotes asymmetry in nuclear $\beta$-catenin, gene expression, and cell fate.

43. Cabello J, Neukomm LJ, Gunesdogan U, Burkart K, Charette SJ, Lochnit G, Hengartner MO, Schnabel R. The Wnt pathway controls cell death engulfment, spindle orientation, and migration through CED- 10/Rac. PLoS Biol. 2010; 8:e1000297. [PubMed: 20126385]

44. Habib SJ, Chen BC, Tsai FC, Anastassiadis K, Meyer T, Betzig E, Nusse R. A localized Wnt signal orients asymmetric stem cell division in vitro. Science. 2013; 339:1445-1448. [PubMed: 23520113] Using Wnt3a beads applied focally to dividing ES cells, this study demonstrates how a local Wnt signal can polarize signaling pathways, orient the plane of division, and promote asymmetric cell fates.

45. Sugimura R, He XC, Venkatraman A, Arai F, Box A, Semerad C, Haug JS, Peng L, Zhong XB, Suda T, et al. Noncanonical Wnt signaling maintains hematopoietic stem cells in the niche. Cell. 2012; 150:351-365. [PubMed: 22817897]

46. Fleming ES, Temchin M, Wu Q, Maggio-Price L, Tirnauer JS. Spindle misorientation in tumors from APC(min/+) mice. Mol Carcinog. 2009; 48:592-598. [PubMed: 19123231]

47. Yamashita YM, Jones DL, Fuller MT. Orientation of asymmetric stem cell division by the APC tumor suppressor and centrosome. Science. 2003; 301:1547-1550. [PubMed: 12970569]

48. Pease JC, Tirnauer JS. Mitotic spindle misorientation in cancer--out of alignment and into the fire. J Cell Sci. 2011; 124:1007-1016. [PubMed: 21402874]

49. Wu X, Shen QT, Oristian DS, Lu CP, Zheng Q, Wang HW, Fuchs E. Skin stem cells orchestrate directional migration by regulating microtubule-ACF7 connections through GSK3beta. Cell. 2011; 144:341-352. [PubMed: 21295697]

50. Watt FM, Huck WT. Role of the extracellular matrix in regulating stem cell fate. Nat Rev Mol Cell Biol. 2013; 14:467-473. [PubMed: 23839578] 
51. Gilbert PM, Havenstrite KL, Magnusson KE, Sacco A, Leonardi NA, Kraft P, Nguyen NK, Thrun S, Lutolf MP, Blau HM. Substrate elasticity regulates skeletal muscle stem cell self-renewal in culture. Science. 2010; 329:1078-1081. [PubMed: 20647425]

52. Chaigne A, Campillo C, Gov NS, Voituriez R, Azoury J, Umana-Diaz C, Almonacid M, Queguiner I, Nassoy P, Sykes C, et al. A soft cortex is essential for asymmetric spindle positioning in mouse oocytes. Nat Cell Biol. 2013

53. Lautenschlager F, Piel M. Microfabricated devices for cell biology: all for one and one for all. Curr Opin Cell Biol. 2013; 25:116-124. [PubMed: 23195438]

54. Thery M, Bornens M. Cell shape and cell division. Curr Opin Cell Biol. 2006; 18:648-657. [PubMed: 17046223]

55. Tan DW, Jensen KB, Trotter MW, Connelly JT, Broad S, Watt FM. Single-cell gene expression profiling reveals functional heterogeneity of undifferentiated human epidermal cells. Development. 2013; 140:1433-1444. [PubMed: 23482486]

56. Mascre G, Dekoninck S, Drogat B, Youssef KK, Brohee S, Sotiropoulou PA, Simons BD, Blanpain C. Distinct contribution of stem and progenitor cells to epidermal maintenance. Nature. 2012; 489:257-262. [PubMed: 22940863]

57. Goulas S, Conder R, Knoblich JA. The par complex and integrins direct asymmetric cell division in adult intestinal stem cells. Cell Stem Cell. 2012; 11:529-540. [PubMed: 23040479] Drosophila intestinal stem cells are emerging as an important model system for adult stem cell biology, and this study describes how ISC ACDs are regulated by a combination of intrinsic (Par proteins) and extrinsic (integrins) factors.

58. Fernandez-Minan A, Martin-Bermudo MD, Gonzalez-Reyes A. Integrin signaling regulates spindle orientation in Drosophila to preserve the follicular-epithelium monolayer. Curr Biol. 2007; 17:683-688. [PubMed: 17363255]

59. Rhyu MS, Jan LY, Jan YN. Asymmetric distribution of numb protein during division of the sensory organ precursor cell confers distinct fates to daughter cells. Cell. 1994; 76:477-491. [PubMed: 8313469]

60. Chenn A, McConnell SK. Cleavage orientation and the asymmetric inheritance of Notch1 immunoreactivity in mammalian neurogenesis. Cell. 1995; 82:631-641. [PubMed: 7664342]

61. Etemad-Moghadam B, Guo S, Kemphues KJ. Asymmetrically distributed PAR-3 protein contributes to cell polarity and spindle alignment in early C. elegans embryos. Cell. 1995; 83:743752. [PubMed: 8521491]

62. Kemphues KJ, Priess JR, Morton DG, Cheng NS. Identification of genes required for cytoplasmic localization in early C. elegans embryos. Cell. 1988; 52:311-320. [PubMed: 3345562]

63. Coumailleau F, Furthauer M, Knoblich JA, Gonzalez-Gaitan M. Directional Delta and Notch trafficking in Sara endosomes during asymmetric cell division. Nature. 2009; 458:1051-1055. [PubMed: 19295516]

64. Cotton M, Benhra N, Le Borgne R. Numb inhibits the recycling of Sanpodo in Drosophila sensory organ precursor. Curr Biol. 2013; 23:581-587. [PubMed: 23523246]

65. Couturier L, Mazouni K, Schweisguth F. Numb localizes at endosomes and controls the endosomal sorting of notch after asymmetric division in Drosophila. Curr Biol. 2013; 23:588-593. [PubMed: 23523245]

66. Jauffred B, Llense F, Sommer B, Wang Z, Martin C, Bellaiche Y. Regulation of centrosome movements by Numb and the Collapsin Response Mediator Protein during Drosophila sensory progenitor asymmetric division. Development. 2013; 140:2657-2668. [PubMed: 23720047] Through dynamic imaging of centrosomes in Drosophila SOP divisions, the authors describe a new role for Numb in controlling centrosome movements.

67. Upadhyay A, Kandachar V, Zitserman D, Tong X, Roegiers F. Sanpodo controls sensory organ precursor fate by directing Notch trafficking and binding gamma-secretase. J Cell Biol. 2013; 201:439-448. [PubMed: 23609534]

68. Mizutani K, Yoon K, Dang L, Tokunaga A, Gaiano N. Differential Notch signalling distinguishes neural stem cells from intermediate progenitors. Nature. 2007; 449:351-355. [PubMed: 17721509] 
69. Bultje RS, Castaneda-Castellanos DR, Jan LY, Jan YN, Kriegstein AR, Shi SH. Mammalian Par3 regulates progenitor cell asymmetric division via notch signaling in the developing neocortex. Neuron. 2009; 63:189-202. [PubMed: 19640478]

70. Das RM, Storey KG. Mitotic spindle orientation can direct cell fate and bias Notch activity in chick neural tube. EMBO Rep. 2012; 13:1030.

71. Kim S, Walsh CA. Numb, neurogenesis and epithelial polarity. Nat Neurosci. 2007; 10:812-813. [PubMed: 17593942]

72. Shinin V, Gayraud-Morel B, Gomes D, Tajbakhsh S. Asymmetric division and cosegregation of template DNA strands in adult muscle satellite cells. Nat Cell Biol. 2006; 8:677-687. [PubMed: 16799552]

73. Kuang S, Kuroda K, Le Grand F, Rudnicki MA. Asymmetric self-renewal and commitment of satellite stem cells in muscle. Cell. 2007; 129:999-1010. [PubMed: 17540178]

74. Kawaguchi D, Furutachi S, Kawai H, Hozumi K, Gotoh Y. Dll1 maintains quiescence of adult neural stem cells and segregates asymmetrically during mitosis. Nat Commun. 2013; 4:1880. [PubMed: 23695674]

75. Dong Z, Yang N, Yeo SY, Chitnis A, Guo S. Intralineage directional Notch signaling regulates selfrenewal and differentiation of asymmetrically dividing radial glia. Neuron. 2012; 74:65-78. [PubMed: 22500631] This study draws many parallels between the oriented cell divisions that occur in mammalian, avian, and zebrafish neurogenesis. The authors identify components of the Notch pathway, including Dll1 and mind bomb as important players in reinforcing cell fate differences during and after cell division in zebrafish.

76. Kusek G, Campbell M, Doyle F, Tenenbaum SA, Kiebler M, Temple S. Asymmetric Segregation of the Double-Stranded RNA Binding Protein Staufen2 during Mammalian Neural Stem Cell Divisions Promotes Lineage Progression. Cell Stem Cell. 2012; 11:505-516. [PubMed: 22902295]

77. Vessey JP, Amadei G, Burns SE, Kiebler MA, Kaplan DR, Miller FD. An asymmetrically localized staufen2-dependent RNA complex regulates maintenance of Mammalian neural stem cells. Cell Stem Cell. 2012; 11:517-528. [PubMed: 22902294] These two studies reveal how a mammalian staufen functions in vertebrate asymmetric neuronal precursor divisions, showing that the number of conserved cell fate determinants in flies and mammals may be greater than initially thought.

78. Gong C, Maquat LE. IncRNAs transactivate STAU1-mediated mRNA decay by duplexing with 3' UTRs via Alu elements. Nature. 2011; 470:284-288. [PubMed: 21307942]

79. Kretz M, Siprashvili Z, Chu C, Webster DE, Zehnder A, Qu K, Lee CS, Flockhart RJ, Groff AF, Chow J, et al. Control of somatic tissue differentiation by the long non-coding RNA TINCR. Nature. 2013; 493:231-235. [PubMed: 23201690]

80. Snippert HJ, van der Flier LG, Sato T, van Es JH, van den Born M, Kroon-Veenboer C, Barker N, Klein AM, van Rheenen J, Simons BD, et al. Intestinal crypt homeostasis results from neutral competition between symmetrically dividing Lgr5 stem cells. Cell. 2010; 143:134-144. [PubMed: 20887898]

81. Lopez-Garcia C, Klein AM, Simons BD, Winton DJ. Intestinal stem cell replacement follows a pattern of neutral drift. Science. 2010; 330:822-825. [PubMed: 20929733]

82. Clayton E, Doupe DP, Klein AM, Winton DJ, Simons BD, Jones PH. A single type of progenitor cell maintains normal epidermis. Nature. 2007; 446:185-189. [PubMed: 17330052]

83. Gladden AB, Hebert AM, Schneeberger EE, McClatchey AI. The NF2 tumor suppressor, Merlin, regulates epidermal development through the establishment of a junctional polarity complex. Dev Cell. 2010; 19:727-739. [PubMed: 21074722]

84. Silvis MR, Kreger BT, Lien WH, Klezovitch O, Rudakova GM, Camargo FD, Lantz DM, Seykora JT, Vasioukhin V. alpha-catenin is a tumor suppressor that controls cell accumulation by regulating the localization and activity of the transcriptional coactivator Yap1. Sci Signal. 2011; 4:ra33. [PubMed: 21610251]

85. Schlegelmilch K, Mohseni M, Kirak O, Pruszak J, Rodriguez JR, Zhou D, Kreger BT, Vasioukhin V, Avruch J, Brummelkamp TR, et al. Yap1 acts downstream of alpha-catenin to control epidermal proliferation. Cell. 2011; 144:782-795. [PubMed: 21376238] 
86. Knoblich JA. Asymmetric cell division: recent developments and their implications for tumour biology. Nat Rev Mol Cell Biol. 2010; 11:849-860. [PubMed: 21102610]

87. Martin-Belmonte F, Perez-Moreno M. Epithelial cell polarity, stem cells and cancer. Nat Rev Cancer. 2012; 12:23-38. [PubMed: 22169974]

88. Xue B, Krishnamurthy K, Allred DC, Muthuswamy SK. Loss of Par3 promotes breast cancer metastasis by compromising cell-cell cohesion. Nat Cell Biol. 2013; 15:189-200. [PubMed: 23263278]

89. McCaffrey LM, Montalbano J, Mihai C, Macara IG. Loss of the Par3 polarity protein promotes breast tumorigenesis and metastasis. Cancer Cell. 2012; 22:601-614. [PubMed: 23153534]

90. Iden S, van Riel WE, Schafer R, Song JY, Hirose T, Ohno S, Collard JG. Tumor type-dependent function of the par3 polarity protein in skin tumorigenesis. Cancer Cell. 2012; 22:389-403. [PubMed: 22975380]

91. Hirose T, Karasawa M, Sugitani Y, Fujisawa M, Akimoto K, Ohno S, Noda T. PAR3 is essential for cystmediated epicardial development by establishing apical cortical domains. Development. 2006; 133:1389-1398. [PubMed: 16510507]

92. Cabernard C, Prehoda KE, Doe CQ. A spindle-independent cleavage furrow positioning pathway. Nature. 2010; 467:91-94. [PubMed: 20811457]

93. Kiyomitsu T, Cheeseman IM. Cortical Dynein and asymmetric membrane elongation coordinately position the spindle in anaphase. Cell. 2013; 154:391-402. [PubMed: 23870127] These authors have paired up to produce two interesting studies showing how LGN, NuMA, and dynein-dynactin function in symmetrically dividing HeLa cells. Using a proteomic approach, they identify the 4.1 band proteins $4.1 \mathrm{G} / \mathrm{R}$ as a novel pathway that functions through NuMA/dynein to position the mitotic spindle at the center of the cell. 
a

Prophase Neuroblast
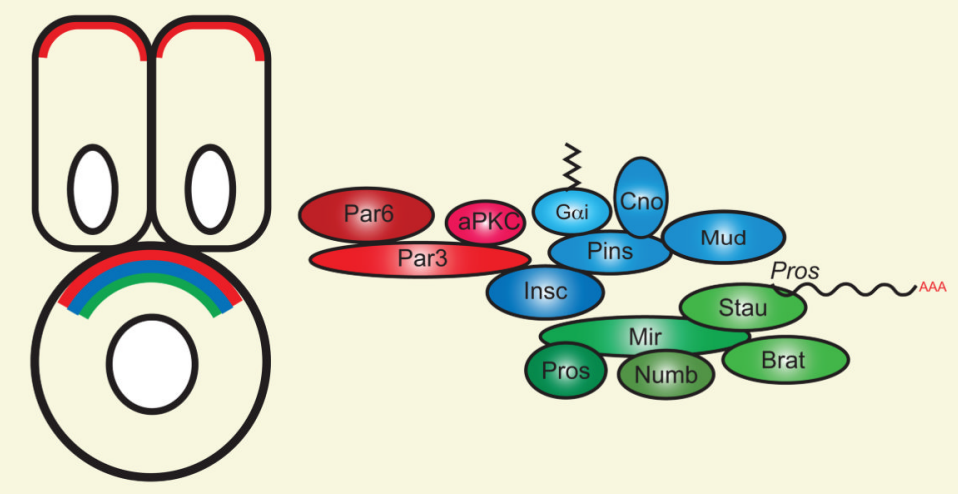

Telophase

Neuroblast

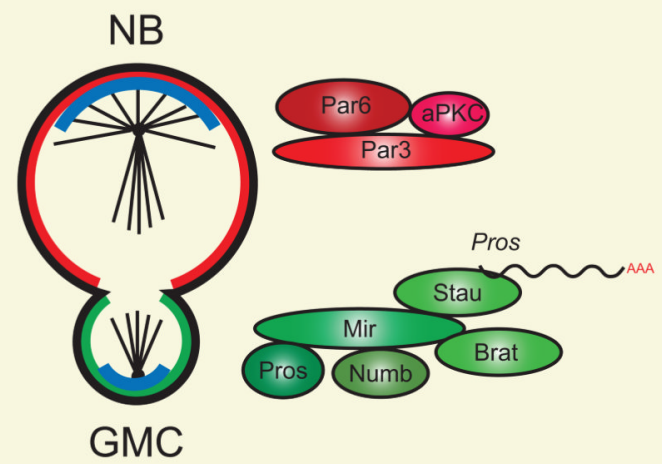

b

\section{Apical Cortex}

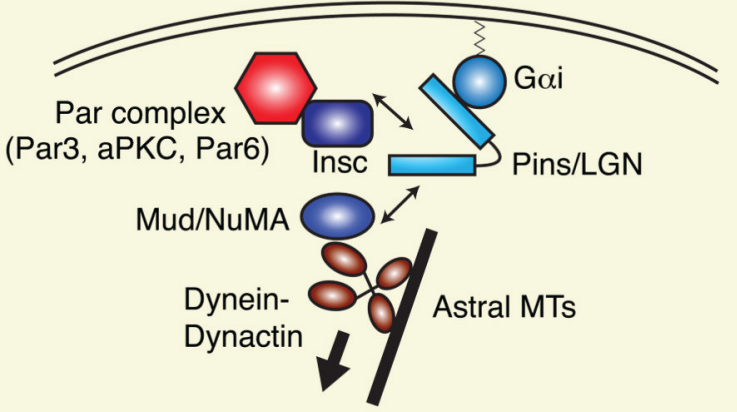

Figure 1. Spindle orientation and asymmetric cell divisions

(a) Summary of some of the major players in spindle orientation, and their subcellular distributions in early (top) and late stage (bottom) mitotic Drosophila NBs. NBs divide by delaminating from the epithelium, generating a larger apical stem cell daughter and a smaller basal ganglion mother cell (GMC), which undergoes further divisions to generate neurons. In red are components of the Par polarity complex (Par3/Bazooka, Par6 and aPKC), which are apically enriched even in interphase. In blue are components of the spindle orientation complex, centered on Pins (LGN/Gpsm2 or AGS3/Gpsm1 in vertebrates). Pins contains N-terminal TPR motifs that bind Insc and Mud (NuMA in 
vertebrates), and C-terminal GoLoco motifs that bind GDP-bound heterotrimeric G-proteins of the Gai and Gao families. These domains are connected by a flexible linker region which contains phosphorylation sites for aPKC and Aurora kinase, and binds other proteins such as Cno and Dlg. Mud is a coiled-coil MT-binding protein which interacts with the dyneindynactin motor complex to "capture" astral MTs and reorient the spindle to apical polarity cues. In green are components of the so-called "basal complex" which contain the cell fate determinants Brat (TRIM-2/3/32 in vertebrates), Numb, Miranda, and Prospero, as well as the RNA-binding protein Staufen. These components are not initially polarized but become basally restricted from metaphase onward, resulting in a classical asymmetric cell division (ACD), differentially partitioning cell fate components. By telophase, the apical restriction of most spindle orientation components is lost. Pins and mInsc are no longer cortical, while Mud forms crescents at both the apical and basal poles, as well as on centrosomes.

(b) Schematic of the interaction of apical complex components, generalized for both fly and vertebrate systems. Pins/LGN's apical association can be mediated both through its binding to Gai (which is linked to the plasma membrane via a GPI anchor) and through Insc/Par3. Pins can bind directly to Insc and to NuMA, but these proteins never form a tripartite complex as Insc and NuMA are competitive interactors. A current model is that Insc functions to hand off Pins to NuMA as mitosis progresses, thus allowing for the engagement with astral MTs via the dynein-dynactin motor complex. 
a b

Neuronal Progenitor

apical (ventricular)

basal

(pial)
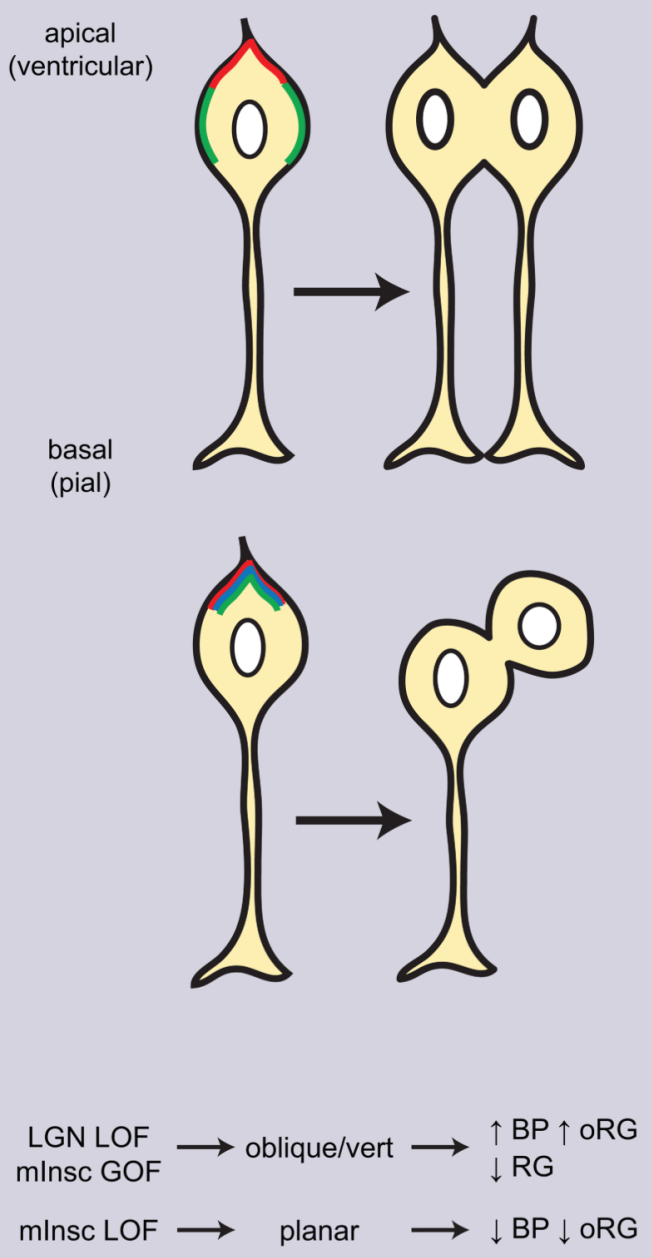

\section{Epidermal Progenitor}
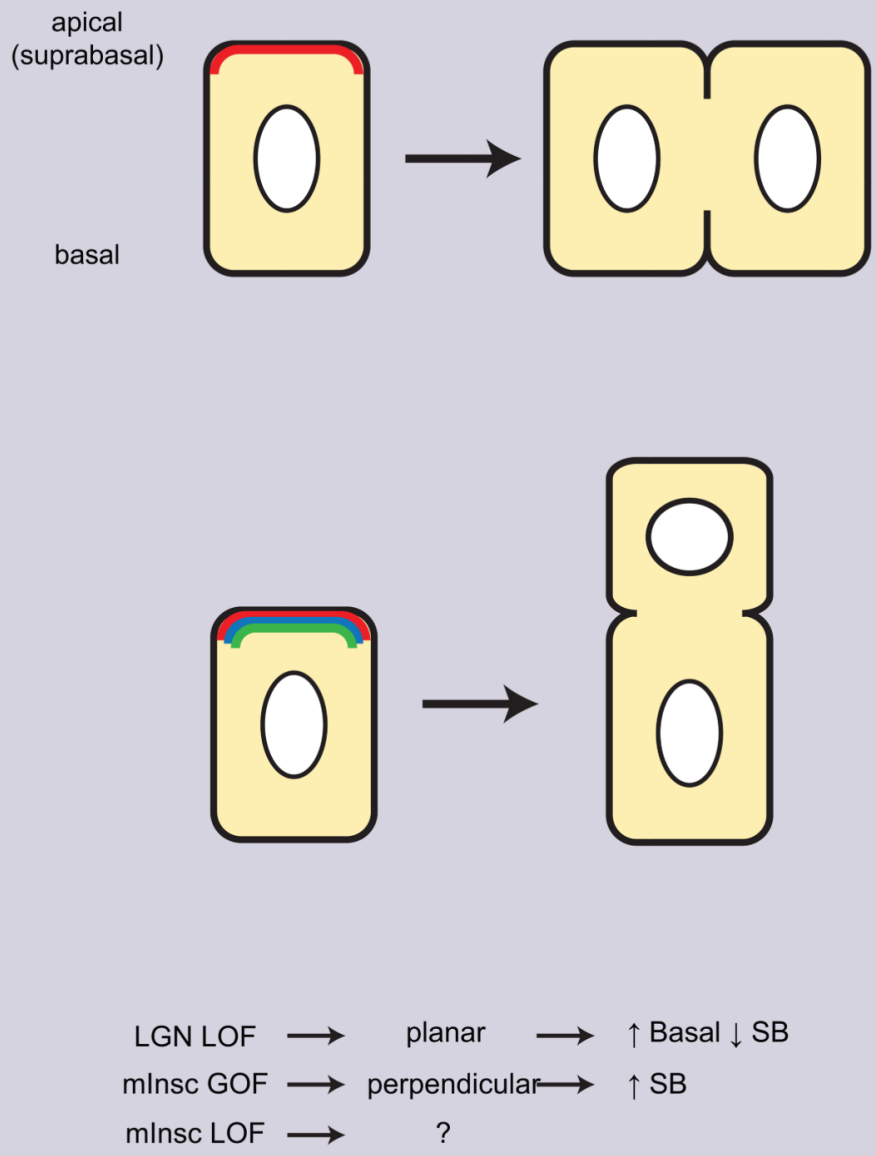

mlnsc

LGN

Figure 2. Role of mInsc and LGN in mammalian neuronal and epidermal progenitors

(a) In planar RG divisions (top), LGN is localized to lateral domains, while the Par complex is localized apically. The phosphorylation of LGN by aPKC is believed to inhibit its apical localization. Such divisions are generally symmetric, giving rise to two RGs, or sometimes one RG and one neuron. In oblique divisions (bottom), mInsc is localized to the apical domain along with the Par complex. Though not directly determined experimentally, it is believed that LGN is also recruited apically through its interaction with mInsc. These divisions are frequently asymmetric, giving rise to one basal/intermediate progenitor (BP), and one outer ventricular zone progenitor (oRG). 
(b) In the epidermis, basal cells show apical expression of the Par complex as in many other epithelia. In planar divisions (top), LGN is absent, which may due to the absence of mInsc, though this has not yet been proven. In perpendicular divisions (bottom), mInsc and LGN form apical crescents. This has been shown to promote asymmetric daughter cell fates, with the apical suprabasal daughter progressing to differentiate, while the basal daughter remains a progenitor. The consequences of gain-of-function (gof) and loss-of-function (lof) studies on spindle orientation and cell fate in both systems are shown at bottom. It is not presently known how loss of mInsc function affects epidermal progenitor divisions. 